\title{
Combined effects of snow depth and nitrogen addition on ephemeral growth at the southern edge of the Gurbantunggut Desert, China
}

\author{
LianLian $\mathrm{FAN}^{1,2}$, Yan $\mathrm{LI}^{1 *}$, LiSong TANG ${ }^{1}$, Jian MA ${ }^{1}$ \\ ${ }^{1}$ State Key Laboratory of Desert and Oasis Ecology, Xinjiang Institute of Ecology and Geography, Chinese Academy of Sciences, \\ Urumqi 830011, China; \\ ${ }^{2}$ University of Chinese Academy of Sciences, Beijing 100049, China
}

\begin{abstract}
Water and nitrogen $(\mathrm{N})$ inputs are considered as the two main limiting factors affecting plant growth. Changes in these inputs are expected to alter the structure and composition of the plant community, thereby influencing biodiversity and ecosystem function. Snowfall is a form of precipitation in winter, and snow melting can recharge soil water and result in a flourish of ephemerals during springtime in the Gurbantunggut Desert, China. A bi-factor experiment was designed and deployed during the snow-covering season from 2009 to 2010 . The experiment aimed to explore the effects of different snow-covering depths and $\mathrm{N}$ addition levels on ephemerals. Findings indicated that deeper snow cover led to the increases in water content in topsoil as well as density and coverage of ephemeral plants in the same $\mathrm{N}$ treatment; by contrast, $\mathrm{N}$ addition sharply decreased the density of ephemerals in the same snow treatment. Meanwhile, $\mathrm{N}$ addition exhibited a different effect on the growth of ephemeral plants: in the $50 \%$ snow treatment, $\mathrm{N}$ addition limited the growth of ephemeral plants, showing that the height and the aboveground biomass of the ephemeral plants were lower than in those without $\mathrm{N}$ addition; while with the increases in snow depth (100\% and $150 \%$ snow treatments), $\mathrm{N}$ addition benefited the growth of the dominant individual plants. Species richness was not significantly affected by snow in the same $\mathrm{N}$ treatment. However, $\mathrm{N}$ addition significantly decreased the species richness in the same snow-covering depth. The primary productivity of ephemerals in the $\mathrm{N}$ addition increased with the increase of snow depth. These variations indicated that the effect of $\mathrm{N}$ on the growth of ephemerals was restricted by water supply. With plenty of water ( $100 \%$ and $150 \%$ snow treatments), $\mathrm{N}$ addition contributed to the growth of ephemeral plants; while with less water ( $50 \%$ snow treatment), $\mathrm{N}$ addition restricted the growth of ephemeral plants.
\end{abstract}

Keywords: snow depth; soil water content; $\mathrm{N}$ addition; ephemeral plant; plant density; species richness

Citation: LianLian FAN, Yan LI, LiSong TANG, Jian MA. 2013. Combined effects of snow depth and nitrogen addition on ephemeral growth at the southern edge of the Gurbantunggut Desert, China. Journal of Arid Land, 5(4): 500-510. doi: 10.1007/s40333-013-0185-8

Global change driven by anthropogenic activities has impacted regional environments (Weltzin et al., 2003; Chang et al., 2012), including precipitation regime change and widespread nitrogen $(\mathrm{N})$ enrichment (IPCC, 2007). Water and $\mathrm{N}$ are two key factors affecting plant growth in terrestrial ecosystems (Yang et al., 2011), and changes in the availability of water and $\mathrm{N}$ markedly influence plant traits (Miranda et al., 2009).
Subsequently, these changes affect ecosystem processes, especially in resource-limited arid deserts (Ladwig et al., 2012; Schmiedel et al., 2012). Thus, understanding how plant communities respond to concurrent alterations in water and $\mathrm{N}$ availabilities under global change scenarios is important.

In arid and semi-arid ecosystems, plant behavior is limited by water availability and $\mathrm{N}$ supply (Zhang and

*Corresponding author: Yan LI (E-mail: liyan@ms.xjb.ac.cn) 
Zak, 1998). Studies have indicated that increased precipitation and $\mathrm{N}$ addition stimulate and suppress community species richness, respectively, and also significantly alter plant community structure and composition at functional group levels (Stevens et al., 2010; Yang et al., 2010). Generally, water supplementation and $\mathrm{N}$ fertilization can increase the density and biomass of annual plants (Gutierrez and Whitford, 1987a; Brooks, 2003), and increased production of grasses often occur under the highest level of soil $\mathrm{N}$ fertilization (Rao and Allen, 2010). However, evidence also suggests that productivity does not vary directly with water input (Gutierrez and Whitford, 1987b), and $\mathrm{N}$ fertilization can reduce the density or biomass of some plants because of competitive stress (Brooks, 2003).

Ephemerals, with their short-term growth rhythm and specific biological traits, can adapt to various environments. They mainly occur in Central Asia, the Mediterranean Coast, West Asia, and North Africa (Lapointe and Lerat, 2006; Constable et al., 2007). Ephemerals are distributed in arid deserts where precipitation is low and highly unpredictable and $\mathrm{N}$ levels are also naturally low. These plants often use limited rainfall and snowmelt water for germination and development (Went, 1942; Wang et al., 2006), and a relatively small increase in the amount of water or $\mathrm{N}$ may significantly change plant traits (Fox, 1990; Vitousek et al., 1997). Zhou et al. (2011) found that $\mathrm{N}$ addition significantly affected the growth of both species of Malcolmia africana and Bassia hyssopifolia; specifically, the root weight, leaf number, average leaf area, total biomass, and the shoot/root ratio all increased with $\mathrm{N}$ addition.

Snowfall is a special form of precipitation, and its melting can recharge soil water and benefit plant growth and development (Wang et al., 2006). Accumulation and ablation of snow has currently been altered by global warming, significantly advancing snowmelt (Dye, 2002; Rikiishi et al., 2004). This change can lead to an earlier onset of the growing season (Shabanov et al., 2002). Generally, water is regarded as the primary limiting factor affecting plant growth in arid regions; however, studies have shown that both water and fertilizer are common limiting factors influencing the growth and recovery of vegetation in arid areas (Austin et al., 2004; Harpole et al., 2007). Nutritional demands of desert herbaceous plants change significantly with environmental variations such as rainfall events. Subsequently, the characteristics of the plant community are influenced by the increase in limited nutrition (Boyer and Zedler, 1999).

In the Gurbantunggut Desert in China, the germination and development of ephemerals primarily depend on the early spring snowmelt water. Nearby farms have recently increased their application of nitrogenous fertilizer. The amount of fertilizer applied rapidly increased from $7.4 \times 10^{7} \mathrm{~kg}$ in 1980 to $4.9 \times 10^{8} \mathrm{~kg}$ in 2004 (Ma et al., 2006). Emission from nearby cities has also enhanced local soil N levels (Xu et al., 2008). This potential source of $\mathrm{N}$ would disperse to adjacent desert ecosystems.

Therefore, a bi-factor field experiment with varying snow depths and $\mathrm{N}$ addition levels was conducted during the snow-covering season from 2009 to 2010 at the southern edge of the Gurbantunggut Desert. This study aims to answer two questions: (1) How do the species traits (height and aboveground biomass) of the ephemeral community respond to $\mathrm{N}$ addition and variation in snow depth? (2) How do $\mathrm{N}$ addition and variation in snow depth affect ephemeral community structure and species richness in an arid desert? Despite the short term of the experiment, this study can elucidate ephemeral sensitivities toward variation in the amounts of water and $\mathrm{N}$ caused by global climate change.

\section{Materials and methods}

\subsection{Study area}

All field work was conducted at the southern edge of the Gurbantunggut Desert $\left(44^{\circ} 12^{\prime}-44^{\circ} 21^{\prime} \mathrm{N}, 87^{\circ} 50^{\prime}-\right.$ $87^{\circ} 54^{\prime} \mathrm{E}, 450 \mathrm{~m}$ asl) from November 2009 to June 2010. The landform of the desert is characterized by fixed and semi-fixed branch-shaped sand dunes, with relative heights ranging from 20 to $30 \mathrm{~m}$. The physiography of this area is mainly characterized by longitudinal sand dunes that visibly run from east to west and south to north. The desert has a typical continental arid climate with hot summers and cold win- 
ters. The annual mean temperature is $6.6^{\circ} \mathrm{C}$, with an annual maximum of $42.6^{\circ} \mathrm{C}$ and an annual minimum of $-41.6^{\circ} \mathrm{C}$. The mean annual precipitation ranges from 70 to $180 \mathrm{~mm}$, and the mean annual potential evaporation is about $2,000 \mathrm{~mm}$. Snow usually covers the land to a depth of $20 \mathrm{~cm}$ for approximately 100 to 160 days, starting in late November and ending in late March of the following year. Accumulated snow rapidly melts in early spring and the melting water is absorbed into the soil (Li, 1991), which highly favors the germination and growth of desert plants, especially ephemerals.

\subsection{Experimental design and treatments}

In November 2009, 15 blocks at 5 sites were established ( 3 blocks at each site). The 3 blocks in each site were treated by $50 \%, 100 \%$, and $150 \%$ snow treatment, respectively. Every block was divided into two $2.5 \mathrm{~m} \times 15 \mathrm{~m}$ parts; one part was treated by $\mathrm{N}$ addition, and the other was not treated by any $\mathrm{N}$ addition (Fig. 1). In each block, six $1 \mathrm{~m} \times 1 \mathrm{~m}$ sampling plots were randomly chosen to monitor the growth of ephemeral plants ( 3 plots for $\mathrm{N}$ addition, and 3 plots for no $\mathrm{N}$ addition).

Snow depth was measured using a regular rule each week from January to March to obtain the stable snow depth. In early March before snowmelt, varying depths of snow were applied to each block: (1) $50 \%$ snow treatment by reducing the snow depth to half of the natural snow depth; (2) 100\% snow treatment by keeping the natural snow depth; and (3) $150 \%$ snow treatment by adding the snow depth to one and half of the natural snow depth. Commercial $\mathrm{NH}_{4} \mathrm{NO}_{3} \mathrm{~N}$ at 10 $\mathrm{g} / \mathrm{m}^{2}$ was added once before snowmelt.

\subsection{Field data processing}

Soil samples were collected when snow had melted and frozen soil had thawed. The samples were taken from topsoil layer at a depth ranging from 0 to $5 \mathrm{~cm}$ after removal of the litter layer. Portions of the soil samples were oven-dried at $105^{\circ} \mathrm{C}$ for over $12 \mathrm{~h}$ and used to calculate the soil water content in each snow treatment. Each snow treatment had 15 replicates. The remaining soil samples were air-dried and hand-sieved through a $0.25-\mathrm{mm}$ mesh. Soil $\mathrm{pH}$ and electrical conductivity (EC) were measured in a soil-water suspension (1:5 soil/water ratio); soil organic carbon (SOC) was measured by the $\mathrm{K}_{2} \mathrm{Cr}_{2} \mathrm{O}_{7}-\mathrm{H}_{2} \mathrm{SO}_{4}$ oxidation method proposed by Walkley-Black (Nelson and Sommers, 1982); and available nitrogen (AN) was determined colorimetrically by the alkali method with a Tecator Kjeltec system 1026 distilling unit (Nelson and Sommers, 1982).

In late May, the seedlings developed into adult plants, and the number of species in each plot was determined. The frequencies of plant species in each snow treatment were recorded according to the number of species present in each plot (Greig-Smith, 1983). The ephemeral density was recorded by counting the plant number in each plot. Floristic similarities for the $\mathrm{N}$ treatments under three snow treatments were compared by calculating Sorensen's index of similarity (IS; Chen et al., 2008):

$$
I S=100 \times[2 c(A+B)] .
$$

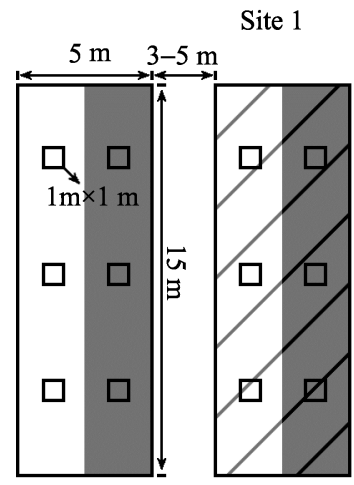

Block 1

Block 2

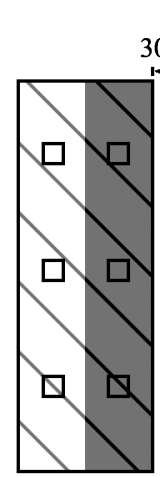

Block 3

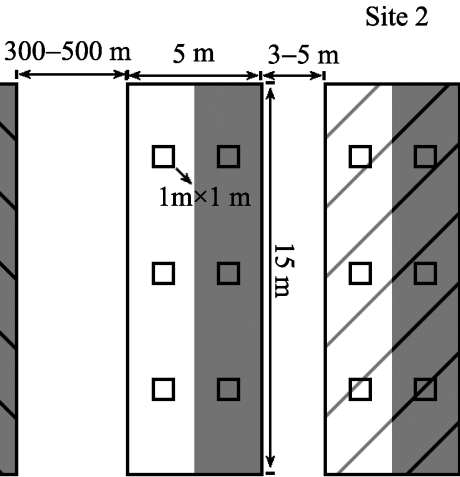

Block 1

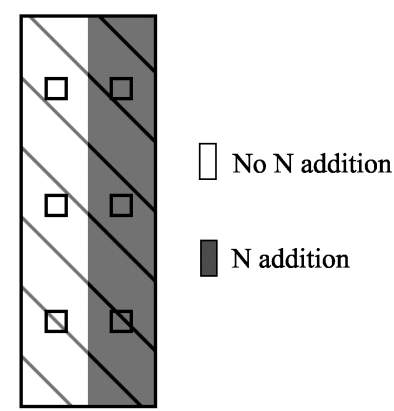

Block 3

Fig. 1 Schematic of the field trial. Block 1 , block 2, and block 3 in each site were treated by $50 \%, 100 \%$, and $150 \%$ snow, respectively. 
Where $c$ is the number of species in common between $\mathrm{N}$ treatments in the same snow treatment, and $A+B$ represents the total number of species between $\mathrm{N}$ treatments in the same snow treatment. The $I S$ value of 100 indicates that $\mathrm{N}$ addition and no $\mathrm{N}$ addition have the same species in the same snow treatment, while the $I S$ value of 0 indicates that $\mathrm{N}$ addition and no $\mathrm{N}$ addition have no same species in the same snow treatment.

During the peak growing season, the density value of each species was recorded by counting its number in each plot. The heights of the ephemerals were also recorded. The point center method (Kershaw and Looney, 1983) was used to estimate the coverage of plant species, and more than 100 points were located randomly in each selected plot. For each species, the number of points that intercepted the individuals of a species was counted and expressed as a percentage of the total number of points used. The percentage cover of each species was then estimated.

Aboveground biomass was measured by the harvest method for dominant species (Nepeta micrantha) during its peak growing period. For each plot, the N. micrantha plants were first harvested to measure the individual aboveground biomass. All plants were then harvested to calculate the layer aboveground biomass. All samples were oven-dried at $75^{\circ} \mathrm{C}$ for $24 \mathrm{~h}$. The individual aboveground biomass is the average value of the first harvest by dividing the number of $N$. micrantha plants. The layer aboveground biomass was the sum of the first and the second harvests.

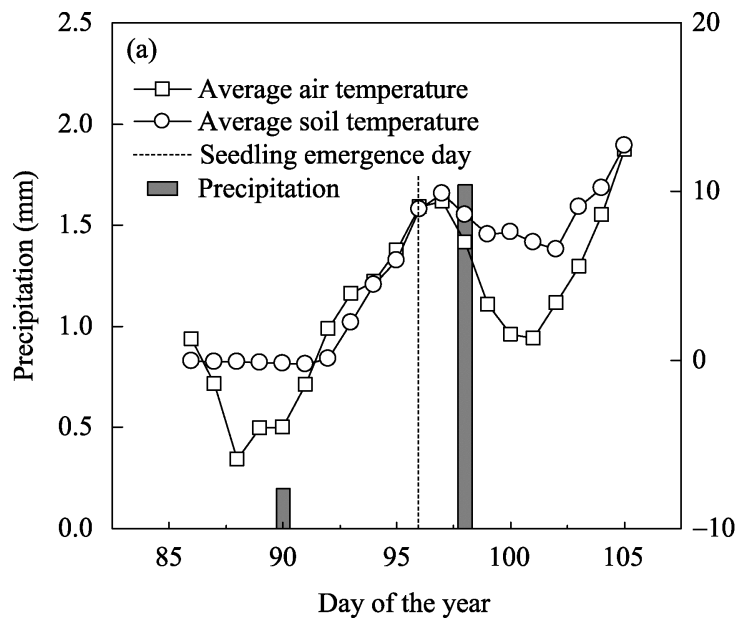

Meteorological data were obtained from an automatic meteorological station located about $500 \mathrm{~m}$ from the experimental site.

\subsection{Data analysis}

Descriptive statistics was employed to calculate the averages and the standard errors of the data from each set of reduplicates expressed as mean \pm standard error. We used one-way and two-way ANOVA to test the differences between the data measured and Tukey's test to test the differences among treatments when ANOVA showed significant effects $(P<0.05)$. All tests were conducted with SPSS version 13.0 for Windows.

\section{Results}

\subsection{Meteorological condition}

Before and after seedling emergence, precipitation occurred twice in 2010; one was measured at $0.2 \mathrm{~mm}$, and the other at $1.7 \mathrm{~mm}$ (Fig. 2a). As indicated in Fig. 2a, before seedling emergence, the air temperature and soil temperature at a depth of $5 \mathrm{~cm}$ continued to increase and reached $9^{\circ} \mathrm{C}$ until the seedling began to emerge. The values slightly declined immediately after seedling emergence and then continued to increase.

During the ephemeral-growing season, 9 precipitation events occurred, with most measuring less than $1 \mathrm{~mm}$ and only one measuring greater than 5 mm (Fig. 2b).

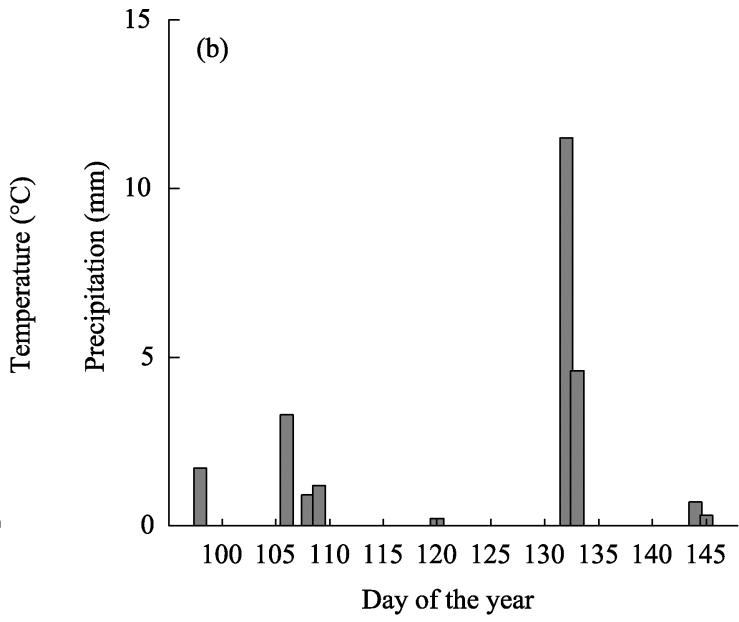

Fig. 2 Average air temperature, average soil temperature at a 5-cm depth, precipitation before and after seedling emergence (a), and precipitation during the ephemeral growth season (b) 


\subsection{Soil properties after snowmelt}

Given the rapid increase in temperature in early spring, snow usually melts away within 3 to 5 days. The amount of melted snow is equivalent to the amount of water from a single heavy rainfall. Thus, with the increase in the depth of snow, soil water content at the depth of $0-5 \mathrm{~cm}$ increased significantly (Table 1 ). The surface soil could retain a certain amount of water. In the $50 \%$ snow treatment, the snow depth was reduced to half of the natural snow depth, and soil water content at the depth of $0-5 \mathrm{~cm}$ was only $6.94 \%$. However, in the $100 \%$ and $150 \%$ snow treatments, the soil water content at the depth of $0-5 \mathrm{~cm}$ increased to $10.37 \%$ and $10.69 \%$, respectively.

No significant differences in $\mathrm{SOC}, \mathrm{EC}$, and $\mathrm{pH}$ were indicated under different snow treatments and $\mathrm{N}$ treatments. However, AN was significantly influenced by $\mathrm{N}$ addition (Table 1 ).

Table 1 Soil properties under different snow treatments and $\mathrm{N}$ treatments (mean \pm SE)

\begin{tabular}{lllll}
\hline \multirow{2}{*}{ Soil property } & \multirow{2}{*}{$\begin{array}{l}\mathrm{N} \\
\text { treatment }\end{array}$} & & \multicolumn{3}{c}{ Snow treatment } \\
\cline { 3 - 5 } SOC $(\%)$ & $\mathrm{N}_{0}$ & $0.57 \pm 0.10$ & $0.58 \pm 0.07$ & $0.38 \pm 0.06$ \\
& $\mathrm{~N}_{1}$ & $0.71 \pm 0.04$ & $0.66 \pm 0.04$ & $0.66 \pm 0.07$ \\
$\mathrm{AN}(\mathrm{g} / \mathrm{kg})$ & $\mathrm{N}_{0}$ & $4.67 \pm 0.78 \mathrm{~B}$ & $4.21 \pm 0.26 \mathrm{~B}$ & $4.10 \pm 0.48 \mathrm{~B}$ \\
& $\mathrm{~N}_{1}$ & $6.83 \pm 0.28 \mathrm{~A}$ & $6.70 \pm 0.24 \mathrm{~A}$ & $6.70 \pm 0.31 \mathrm{~A}$ \\
$\mathrm{EC}(\mathrm{ds} / \mathrm{m})$ & $\mathrm{N}_{0}$ & $54.65 \pm 0.47$ & $50.80 \pm 2.28$ & $51.45 \pm 3.34$ \\
& $\mathrm{~N}_{1}$ & $51.83 \pm 1.30$ & $53.14 \pm 1.64$ & $53.59 \pm 1.85$ \\
pH & $\mathrm{N}_{0}$ & $9.51 \pm 0.04$ & $9.47 \pm 0.04$ & $9.53 \pm 0.03$ \\
& $\mathrm{~N}_{1}$ & $9.31 \pm 0.03$ & $9.20 \pm 0.06$ & $9.28 \pm 0.04$ \\
Water content in & & & & \\
topsoil $(0-5 \mathrm{~cm})$ & & $6.94 \pm 0.84 \mathrm{~b}$ & $10.37 \pm 1.48 \mathrm{a}$ & $10.69 \pm 1.14 \mathrm{a}$ \\
after snowmelt (\%) & & & & \\
\hline
\end{tabular}

Note: SOC denotes soil organic carbon, AN denotes available nitrogen, and EC denotes electrical conductivity. $\mathrm{N}_{0}$ indicates no nitrogen addition, whereas $\mathrm{N}_{1}$ indicates nitrogen addition. $50 \%, 100 \%$, and $150 \%$ snow treatments represent half of the natural snow depth, the natural snow depth, and one and half of the natural snow depth, respectively. Different lowercase letters represent significant differences among snow treatments with the same $\mathrm{N}$ treatment, and different capital letters represent significant differences among $\mathrm{N}$ treatments with the same snow treatment $(P<0.05)$.

\subsection{Density and coverage of ephemeral plants}

The density of adult ephemeral plants was influenced significantly by the quantity of both snow and $\mathrm{N}$ additions. A greater amount of snow indicated higher plant density regardless of $\mathrm{N}$ addition. The highest plant density was observed in the $150 \%$ snow treatment (Fig. 3a). The result revealed that $\mathrm{N}$ addition negatively affected the density of ephemeral plants under the same snow treatment (Fig. 3a).
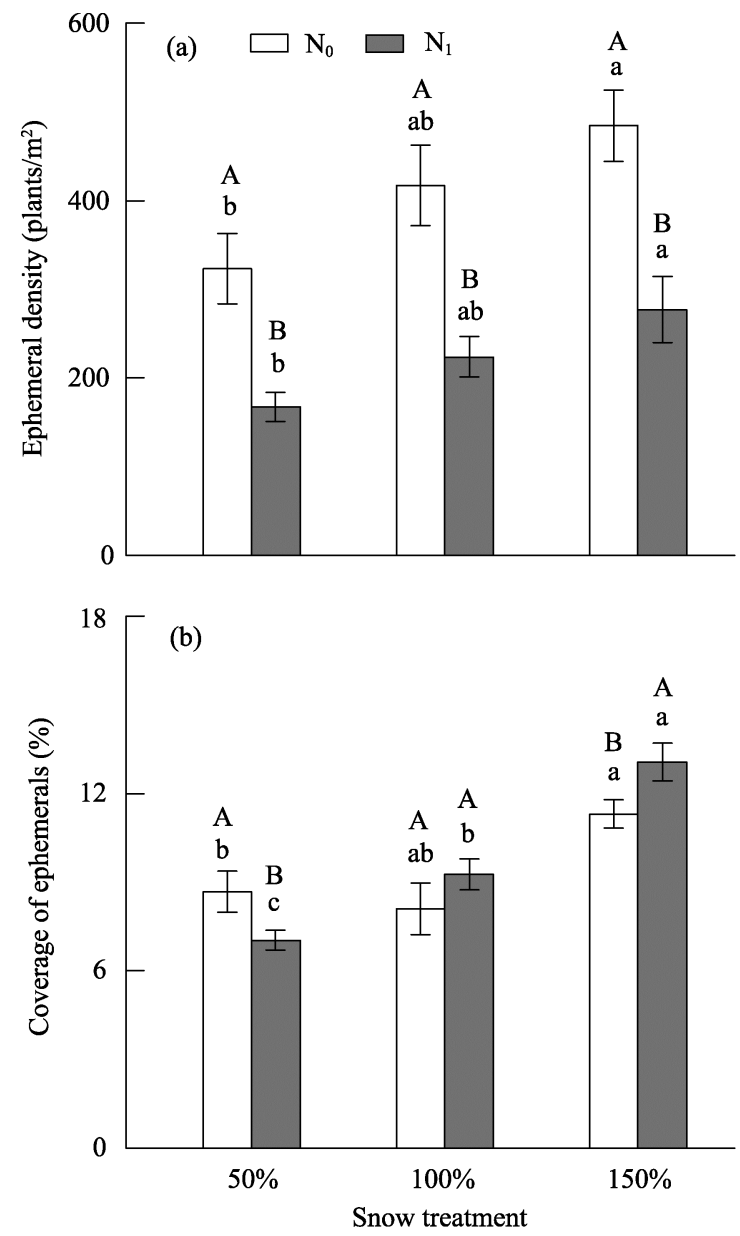

Fig. 3 Ephemeral density (a) and coverage of ephemerals (b) under different snow treatments and $\mathrm{N}$ treatments (mean $\pm \mathrm{SE}$ )

Similar to the density of the ephemeral plants, the layer coverage sharply increased with the increase in snow depth (Fig. 3b). However, $\mathrm{N}$ addition seemed to exhibit a different effect on the coverage of the ephemeral plants. $\mathrm{N}$ addition did not favor ephemeral plant growth when the snow depth was reduced. In the $50 \%$ snow treatment, the ephemeral plants had lower coverage in the treatment with $\mathrm{N}$ addition than in that without $\mathrm{N}$ addition. However, with the increase in snow depth, the ephemeral plants seemingly exhibited increased growth in the treatment with $\mathrm{N}$ addition. The coverage of ephemeral plants in the $100 \%$ and 
$150 \%$ snow treatments increased with $\mathrm{N}$ addition relative to the treatments without $\mathrm{N}$ addition.

\subsection{Plant growth}

The average height and aboveground biomass of the dominant species (N. micrantha) are presented in Fig. 4. The figure indicates that the snow depth negatively affects the average height and the aboveground biomass of the dominant species in the treatment without $\mathrm{N}$ addition. The more plants, the more serious competition of water resources. Corresponding to the plant density shown in Fig. 3a, without $\mathrm{N}$ addition, increased snow depth resulted in reduced plant height. The dominant species in the $50 \%$ snow treatment reached a maximum height of $9.9 \mathrm{~cm}$; and this height was greater than those in the $100 \%$ and $150 \%$ snow treatments (Fig. 4a). The aboveground biomass of individual plants decreased similarly with the height as
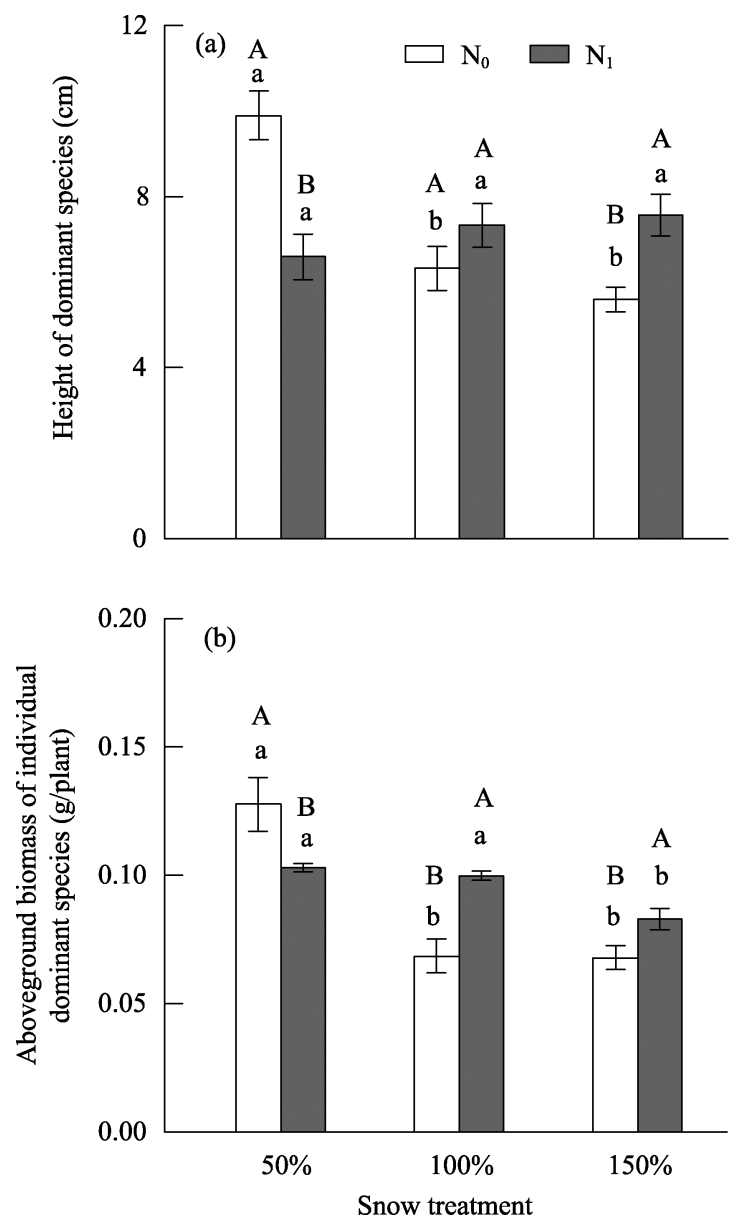

Fig. 4 Height of dominant species (a) and aboveground biomass of individual dominant species (b) under different snow treatments and $\mathrm{N}$ treatments (mean $\pm \mathrm{SE}$ ) the depth of snow increased in the treatment without $\mathrm{N}$ addition. The lowest value of aboveground biomass of individual dominant species was found in the $150 \%$ snow treatment without $\mathrm{N}$ addition (Fig. 4b). However, $\mathrm{N}$ addition exhibited a complex effect. With the increase in the amount of snow (100\% and $150 \%$ snow treatments), more additional $\mathrm{N}$ was contributed to the soil; therefore, the height and the aboveground biomass of the ephemeral plants in the treatments with $\mathrm{N}$ addition were greater than those in the treatments without $\mathrm{N}$ addition.

\subsection{Primary productivity, species richness, and $I S$}

The layer aboveground biomass of the ephemeral plants is shown in Fig. 5. Without $\mathrm{N}$ addition, the layer aboveground biomass of the ephemeral plants showed no significant differences among the different snow treatments. This finding suggests that with other conditions remaining constant, the change in snow depths exhibits no significant effect on the aboveground biomass of the ephemeral plant layer. By contrast, marked changes resulting from the combined effect of snow and $\mathrm{N}$ nutrition were observed among the treatments with $\mathrm{N}$ addition. The aboveground biomass of the ephemeral plant layer (Fig. 5) indicated a similar tendency with the height of dominant species (Fig. 4) after $\mathrm{N}$ addition. With reduced snow depth (50\% snow treatment), the aboveground biomass of the ephemeral plant layer was greater in the treatment without $\mathrm{N}$ addition than in that with $\mathrm{N}$ addition (Fig. 5). However, with increased snow depth (150\% snow treatment),

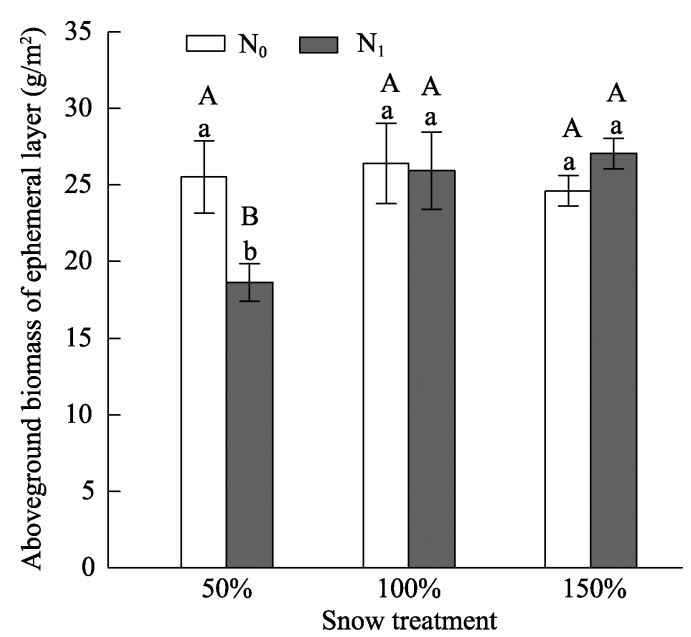

Fig. 5 Total aboveground biomass of the ephemeral layer under different snow treatments and $\mathrm{N}$ treatments (mean $\pm \mathrm{SE}$ ) 
the aboveground biomass of the ephemeral plant layer was greater in the treatment with $\mathrm{N}$ addition than in that without $\mathrm{N}$ addition.

The average species number changed slightly among snow treatments with the same $\mathrm{N}$ treatment (Fig. 6a). However, compared to the treatment without $\mathrm{N}$ addition, the number of species decreased significantly after $\mathrm{N}$ addition in the same snow treatment. About five species grew pre-plot when $\mathrm{N}$ was added. The changes in frequency of ephemerals also demonstrated that the number of species decreased with $\mathrm{N}$ addition in the same snow treatment (Table 2).

The IS between $\mathrm{N}$ treatment and no $\mathrm{N}$ treatment under the same snow depth indicates that species replacement was small in the $50 \%$ snow treatment and that the $I S$ could exceed $80 \%$ with or without $\mathrm{N}$ addition (Fig. 6b). When snow depth increased (100\% and $150 \%$ snow treatments), the $I S$ decreased to $60 \%$ and were significantly lower than that in the $50 \%$ snow treatment.

\section{Discussion}

As special ecotype plants and unique components of desert flora in Western China, ephemeral plants have adapted to the special environment by gradually following the retreat of the ancient Mediterranean Sea. The experiment in the Gurbantunggut Desert demon-

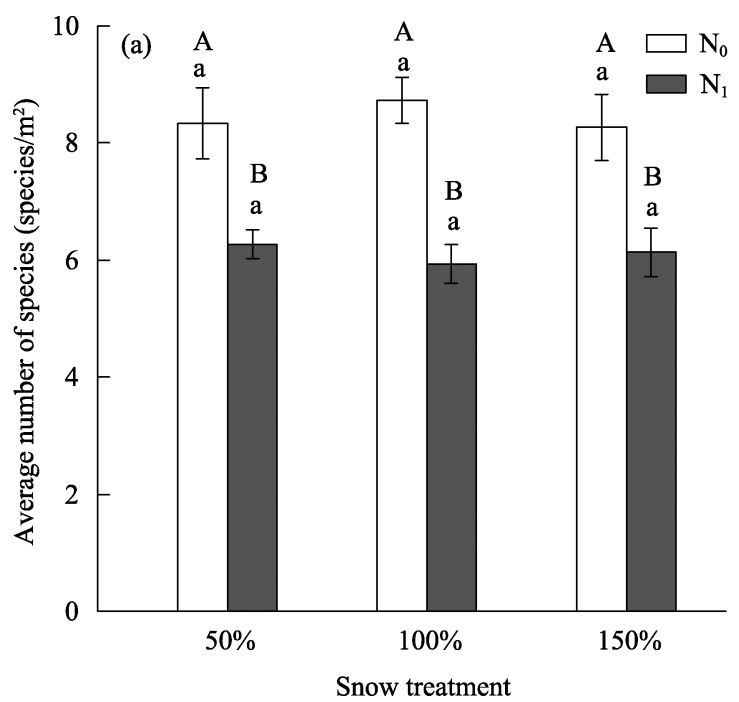

strated that both water and $\mathrm{N}$ nutrition influence the growth of ephemeral plants. Water availability is considered the main factor affecting germination and seedling survival of plants in an arid environment (Went, 1949; Gutterman, 2000). Variations in precipitation can thus influence annual dynamics of plant population through "water limitation" (Levine et al., 2008). Changes in snow depth caused significant differences in soil water contents in early spring. These differences could last for two weeks, and as expected, by water limitation mechanism, the density of ephemerals was positively correlated with the increase in the amount of snow.

Generally, $\mathrm{N}$ is recognized as the primary limiting nutrient for plant growth (LeBauer and Treseder, 2008; Ladwig et al., 2012). Therefore, $\mathrm{N}$ fertilization can directly affect plant growth by improving soil $\mathrm{N}$ availability in N-limited ecosystems (Frink et al., 1999). However, in our experiment, $\mathrm{N}$ fertilization exerted a complex effect. The density of ephemeral plants remarkably decreased in the three different snow treatments with $\mathrm{N}$ addition relative to the treatment without $\mathrm{N}$ addition. The data indicated that $\mathrm{N}$ fertilization did not always benefit the growth of ephemeral plants; by contrast, water supplying had an important function in influencing the effect of $\mathrm{N}$ addition. In the treatment with $50 \%$ snow depth, the limited availability of water restricted the effect of

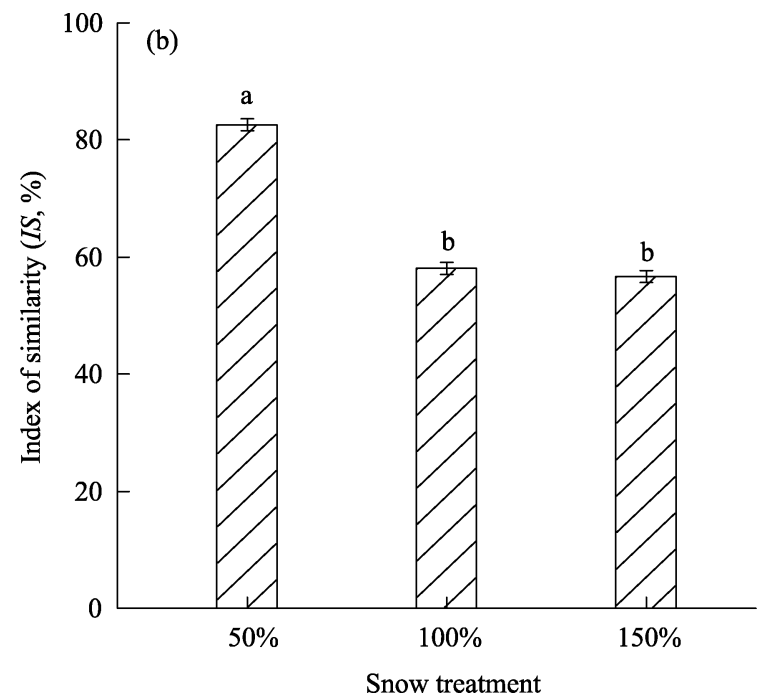

Fig. 6 Average number of ephemeral plant species under different snow treatments and $\mathrm{N}$ treatments (a) and index of similarity (IS) between $\mathrm{N}$ treatment and no $\mathrm{N}$ treatment under the same snow treatment (b) (mean $\pm \mathrm{SE}$ ) 
Table 2 Frequency (\%) of ephemeral plants under different snow treatments and $\mathrm{N}$ treatments

\begin{tabular}{|c|c|c|c|c|c|c|}
\hline \multirow{2}{*}{ Species } & \multicolumn{2}{|c|}{$50 \%$ snow treatment } & \multicolumn{2}{|c|}{$100 \%$ snow treatment } & \multicolumn{2}{|c|}{$150 \%$ snow treatment } \\
\hline & $\mathrm{N}_{0}$ & $\mathrm{~N}_{1}$ & $\mathrm{~N}_{0}$ & $\mathrm{~N}_{1}$ & $\mathrm{~N}_{0}$ & $\mathrm{~N}_{1}$ \\
\hline Nepeta micrantha & 100.00 & 80.00 & 100.00 & 86.67 & 100.00 & 53.33 \\
\hline Schismus arabicus & 93.33 & 60.00 & 93.33 & 73.33 & 100.00 & 73.33 \\
\hline Euphorbia turczaninowii & 60.00 & 33.33 & 53.33 & 60.00 & 46.67 & 33.33 \\
\hline Ceratocarpus arenarius & 66.67 & 66.67 & 93.33 & 53.33 & 86.67 & 60.00 \\
\hline Alyssum linifolium & 46.67 & 66.67 & 73.33 & 73.33 & 40.00 & 53.33 \\
\hline Erodium oxyrrhynchum & 13.33 & 66.67 & 53.33 & 60.00 & 80.00 & 46.67 \\
\hline Orostachys spinosus & 53.33 & 13.33 & 40.00 & 20.00 & 66.67 & 40.00 \\
\hline Lactuca undulata & 20.00 & 46.67 & 73.33 & 60.00 & 40.00 & 53.33 \\
\hline Eremurus inderiensis & 60.00 & 66.67 & 60.00 & 33.33 & 66.67 & 46.67 \\
\hline Koelpinia linearis & 26.67 & 26.67 & 6.67 & 13.33 & 13.33 & 13.33 \\
\hline Hyalea pulchella & 26.67 & 26.67 & 60.00 & 73.33 & 53.33 & 13.33 \\
\hline Trigonella arcuata & 26.67 & 26.67 & 33.33 & 46.67 & 33.33 & 26.67 \\
\hline Tragopogon kasahstanicus & 26.67 & 13.33 & 20.00 & 13.33 & 13.33 & 6.67 \\
\hline Hypecoum parviflorum & 0.00 & 0.00 & 0.00 & 6.67 & 13.33 & 0.00 \\
\hline Corispermum lehmannianum & 6.67 & 33.33 & 0.00 & 6.67 & 0.00 & 13.33 \\
\hline Lappula myosotis & 40.00 & 20.00 & 13.33 & 13.33 & 33.33 & 0.00 \\
\hline Horaninowia ulicina & 13.33 & 0.00 & 13.33 & 0.00 & 13.33 & 0.00 \\
\hline Eremopyrum orientale & 0.00 & 13.33 & 0.00 & 13.33 & 0.00 & 0.00 \\
\hline Epilasia acrolasia & 0.00 & 0.00 & 0.00 & 6.67 & 0.00 & 0.00 \\
\hline Hypecoum erectum & 13.33 & 6.67 & 20.00 & 0.00 & 0.00 & 0.00 \\
\hline Agriophyllum squarrosum & 13.33 & 6.67 & 6.67 & 6.67 & 20.00 & 6.67 \\
\hline Nonea caspica & 0.00 & 13.33 & 6.67 & 6.67 & 13.33 & 0.00 \\
\hline Amberboa turanica & 0.00 & 0.00 & 26.67 & 0.00 & 13.33 & 0.00 \\
\hline Descurainia sophia & 13.33 & 0.00 & 40.00 & 0.00 & 13.33 & 13.33 \\
\hline Alyssum minus & 0.00 & 0.00 & 6.67 & 6.67 & 13.33 & 0.00 \\
\hline Astragalus arpilobus & 0.00 & 0.00 & 0.00 & 13.33 & 0.00 & 40.00 \\
\hline Salsola nitraria & 13.33 & 0.00 & 13.33 & 13.33 & 26.67 & 13.33 \\
\hline Soranthus meyeri & 0.00 & 0.00 & 0.00 & 0.00 & 13.33 & 0.00 \\
\hline Silene nana & 6.67 & 20.00 & 6.67 & 6.67 & 0.00 & 0.00 \\
\hline Bromus tectorum & 0.00 & 0.00 & 6.67 & 6.67 & 0.00 & 0.00 \\
\hline Arnebia guttata & 6.67 & 0.00 & 6.67 & 0.00 & 13.33 & 0.00 \\
\hline Gagea nigra & 0.00 & 0.00 & 0.00 & 0.00 & 0.00 & 0.00 \\
\hline Zygophyllum pterocarpum & 0.00 & 0.00 & 0.00 & 0.00 & 6.67 & 0.00 \\
\hline Malcolmia scorpioides & 0.00 & 0.00 & 0.00 & 0.00 & 0.00 & 6.67 \\
\hline Ixeridium gramineum & 0.00 & 0.00 & 0.00 & 6.67 & 0.00 & 6.67 \\
\hline
\end{tabular}

additional $\mathrm{N}$, and more $\mathrm{N}$ was lost as $\mathrm{NH}_{3}$. Subsequently, the height and the aboveground biomass of the dominant species were relatively small with $\mathrm{N}$ addition. However, with the increase in snow depth (100\% and $150 \%$ snow treatments), more $\mathrm{N}$ was contributed to the soil than was lost to the air. Therefore, ephemeral plants obtained greater heights and aboveground biomasses in the treatments with $\mathrm{N}$ addition than in those without $\mathrm{N}$ addition. The result for the aboveground biomass of ephemeral layer showed a similar tendency with the height of dominant species after $\mathrm{N}$ addition. These behaviors indicated that $\mathrm{N}$ ad- 
dition negatively influenced the growth of ephemeral plants in the treatment with less snow depth (50\%), but positively influenced the growth of ephemeral plants in the treatments with greater snow depth $(100 \%$ and $150 \%)$.

Identification of the limiting nutrient was necessary to determine the effects of $\mathrm{N}$ addition and changes in the depth of snow on community characteristics (coverage, density, height, and aboveground biomass). The ephemeral plants exhibited a complex response to limitations in $\mathrm{N}$ and water. A decrease in the density of ephemerals attributed to $\mathrm{N}$ addition may be the toxic effect of the $\mathrm{N}$ addition (Goldberg and Miller, 1990). This effect possibly occurred at the early growth stage because the height and the aboveground biomass of dominant species were not decreased with $\mathrm{N}$ addition in the late growth stage.

The increase in the depth of snow negatively influenced the height and the aboveground biomass of individual plants in the treatment without $\mathrm{N}$ addition (Fig. 4). However, on the level of ephemeral plant layer, the aboveground biomass did not show the same response to the changes in the depth of snow (Fig. 5). Without $\mathrm{N}$ addition, variations in the amount of snow positively affected plant density and coverage (Fig. 3) and negatively influenced the height and the aboveground biomass of individual plants (Fig. 4). This combination of effect eliminated the influence of snow depth on primary productivity (Fig. 5); however, $\mathrm{N}$ addition changed this tendency. In the treatment with less snow ( $50 \%$ snow treatment), $\mathrm{N}$ addition restricted the growth of ephemeral plants (Fig. 4). This restriction resulted in a decrease of aboveground biomass in the ephemeral plant layer. With increases in snow depth (100\% and 150\% snow treatments), $\mathrm{N}$ addition benefited the growth of ephemeral plants, thereby increasing the aboveground biomass of the ephemeral plant layer. These findings indicated that water availability governed the effects of $\mathrm{N}$ addition.

Although water was a limited resource in the arid land, the variations in the amount of snow showed no significant influence on species richness (Fig. 6a). Adler and Levine (2007) suggested that plant species richness increases with an increase in mean annual precipitation. Moreover, several researchers found that most plants have an optimal range of snow depth, leading to dissimilar biodiversity among different snow depths (Walker et al., 1993; Chen et al., 2008). However, species richness was not significantly affected by different snow depths in our experiment. Every snow treatment exhibited similar variations of species richness. In the treatments without $\mathrm{N}$ addition, the average number of species per plot was 8 (Fig. 6a). Low and uncertain precipitation characterizes the arid land. Rainfall often occurs sporadically and leads to pulse-interpulse cycles of resource availability. The pulsed opportunities provide serious challenges for plant growth and reproduction. These challenges cause certain evolutions in which local plants adapt to the environment and take advantage of these opportunities to persist despite harsh environments. Plants that live in an environment with limited water resources have a species-specific strategy that responds to precipitation variation (Xu et al., 2007; Bloor et al., 2010). In the present study, the ephemerals often germinated after snowmelt and completed their life span ranging from 2 to 3 months. Snow depth variability was found to exert no significant effect on species richness in the same $\mathrm{N}$ treatment, suggesting that every species had the opportunity to germinate, and a small amount of snow can satisfy the water demand for the establishment of fewer individuals. The limited water resource could not support the growth of a large number of plants, but ephemerals could germinate and complete their life span by reducing the number of total individuals. This special strategy could prevent species loss given a large variation in precipitation in the arid land.

Snow depth change exerted no significant effect on species richness in the same $\mathrm{N}$ treatment, but species richness was decreased significantly in the same snow treatment after $\mathrm{N}$ addition. Similar to the findings in other studies (Suding et al., 2005; Reynolds et al., 2007), $\mathrm{N}$ addition sharply decreased species richness. This reduction could be attributed to the disruption of the mechanism of co-existence by $\mathrm{N}$ enrichment, leading to a decrease in diversity by favoring a small number of opportunistic species (Bai et al., 2010). The species with more powerful ability to obtain nutrients can grow better. Therefore, $\mathrm{N}$ addition generally reduces species richness by favoring certain species. 
This finding is verified by the $I S$ shown in Fig. $6 \mathrm{~b}$. With an increase in the amount of snow, $\mathrm{N}$ addition became more favorable to certain species, especially the dominant ones. Given their weak competitive ability, certain species had the tendency to lose the opportunity to survive despite nutrient enrichment. The large amount of water simultaneously simulated the effect of $\mathrm{N}$ on plant growth. Consequently, the $I S$ was lower in the treatment with a larger amount of snow than in those with less amount of snow. The random-loss hypothesis predicts that rare species account for most of the decline in species diversity with fertilization (Oksanen, 1996; Stevens and Carson, 2002; Suding et al., 2005). Our data partially support this hypothesis. Table 2 shows that $\mathrm{N}$ fertilization exerts a reduced effect on the frequency of common species and that rare species changed significantly because of nutrient enrichment.

\section{Conclusions}

Water and $\mathrm{N}$ are considered two main limiting factors affecting plant growth. Therefore, changes in water availability and $\mathrm{N}$ input are expected to alter the structure and composition of the plant community, especially in arid and semi-arid ecosystems. Our findings indicated that both water and $\mathrm{N}$ governed the growth of ephemeral plants and that the $\mathrm{N}$ availability was regulated by the amount of water: in the $50 \%$ snow treatment, $\mathrm{N}$ addition limited the growth of ephemeral plants, as indicated by their lower height and aboveground biomass; while the effect of $\mathrm{N}$ addition on the growth of ephemeral plants was stimulated by the increase in the amount of water $(100 \%$ and $150 \%$ snow treatments). $\mathrm{N}$ addition contributed to the growth of ephemeral plants as the primary productivity increased while water supply was sufficient. The species richness decreased after $\mathrm{N}$ addition in the same snow treatment, whereas snow depth changes exerted no significant effect on the species richness in the same $\mathrm{N}$ treatment.

\section{Acknowledgements}

This work was funded by the National Basic Research Program of China (2009CB825102), the National Basic Research Program of China (2009CB421102E), the International Science \& Technology Cooperation Program of China (2010DFA92720), and the Natural Science Foundation of China (4117049).

\section{References}

Adler P B, Levine L M. 2007. Contrasting relationships between precipitation and species richness in space and time. Oikos, 116(2): 221-232.

Austin A T, Yahdjian L, Stark J M, et al. 2004. Water pulses and biochemical cycle in arid and semiarid ecosystems. Oecologia, 141(2): 221-235.

Bai Y F, Wu J G, Clark C M, et al. 2010. Tradeoffs and thresholds in the effects of nitrogen addition on biodiversity and ecosystem functioning: evidence from Inner Mongolia Grasslands. Global Change Biology, 16(1): 358-372.

Bloor J M G B, Pichon P, Falcimagne R, et al. 2010. Effects of warming, summer drought, and $\mathrm{CO}_{2}$ enrichment on aboveground biomass production, flowering phenology, and community structure in an upland grassland ecosystem. Ecosystems, 13: 888-900.

Boyer K E, Zedler J B. 1999. Nitrogen addition could shift plant community composition in a restored California salt marsh. Restoration Ecology, 7(1): 74-85.

Brooks M L. 2003. Effects of increased soil nitrogen on the dominance of alien annual plants in the Mojave Desert. Journal of Applied Ecology, 40(2): 344-353.

Chang Z F, Zhu S J, Han F G, et al. 2012. Differences in response of desert plants of different ecotypes to climate warming: a case study in Minqin, Northwest China. Journal of Arid Land, 4(2): 140-150.

Chen W N, Wu Y, Wu N, et al. 2008. Effect of snow-cover duration on plant species diversity of alpine meadows on the eastern Qinghai-Tibetan Plateau. Journal of Mountain Science, 5(4): 327-339.

Constable J V H, Peffer B J, DeNicola D M. 2007. Temporal and light-based changes in carbon uptake and storage in the spring ephemeral Podophyllum peltatum (Berberidaceae). Environmental and Experimental Botany, 60(1): 112-120.

Dye D G. 2002. Variability and trends in the annual snow-cover cycle in Northern Hemisphere land areas, 1972-2000. Hydrological Processes, 16(15): 3065-3077.

Fox G A. 1990. Drought and the evolution of flowering time in desert annuals. American Journal of Botany, 77(11): 1508-1518.

Frink C R, Waggoner P E, Ausubel J H. 1999. Nitrogen fertilizer: retrospect and prospect. PNAS, 96(4): 1175-1180.

Goldberg D E, Miller T E. 1990. Effects of different resource additions of species diversity in an annual plant community. Ecology, 71(1): 213-225.

Greig-Smith P. 1983. Quantitative Plant Ecology (3 ${ }^{\text {rd }}$ ed.). Oxford: Blackwell.

Gutierrez J R, Whitford W G. 1987a. Chihuahuan Desert annuals: importance of water and nitrogen. Ecology, 68(6): 2032-2045.

Gutierrez J R, Whitford W G. 1987b. Responses of Chihuahuan Desert herbaceous annuals to rainfall augmentation. Journal of Arid Environments, 12: 127-129.

Gutterman Y. 2000. Environmental factors and survival strategies of 
annual plant species in the Negev Desert, Israel. Plant Species Biology, 15(2): 113-125.

Harpole W S, Potts D L, Suding K N. 2007. Ecosystem responses to water and nitrogen amendment in a California grassland. Global Change Biology, 13(11): 2341-2348.

IPCC. 2007. Climatic Change 2007: The Physical Science Basis: Summary for Policymakers. IPCC WGI Fourth Assessment Report. New York: Cambridge University Press.

Kershaw K A, Looney J H. 1983. Quantitative and Dynamic Plant Ecology. London: Edward Arnold.

Ladwig L M, Collins S L, Swann A L, et al. 2012. Above- and below ground responses to nitrogen addition in a Chihuahuan Desert grassland. Oecologia, 169(1): 177-185.

Lapointe L L L, Lerat S L S. 2006. Annual growth of the spring ephemeral Erythronium americanum as a function of temperature and mycorrhizal status. Canadian Journal of Botany, 84(1): 39-48.

LeBauer D S, Treseder K K. 2008. Nitrogen limitation of net primary productivity in terrestrial ecosystems is globally distributed. Ecology, 89: 371-379.

Levine J M, McEachern A K, Cowan C. 2008. Rainfall effects on rare annual plants. Journal of Ecology, 96: 795-806.

Li J F. 1991. Xinjiang Climate. Beijing: China Meteorological Press.

Ma X, Tian C Y, Feng G, et al. 2006. Spatio-temporal change of the application of chemical fertilizers in Xinjiang. Arid Land Geography, 29(3): 286-294.

Miranda J D, Padilla F M, Lázaro R, et al. 2009. Do changes in rainfall patterns affect semiarid annual plant communities? Journal of Vegetation Science, 20(2): 269-276.

Nelson D W, Sommers L E. 1982. Total carbon, organic carbon, and organic matter. In: Page A L, Miller R H, Keeney D R. Methods of Soil Analysis (Part 2): Chemical and Microbial Properties. Madison: American Society of Agronomy, 539-552.

Oksanen J. 1996. Is the humped relationship between species richness and biomass an artefact due to plot size? Journal of Ecology, 84: 293-295.

Rao L E, Allen E B. 2010. Combined effects of precipitation and nitrogen deposition on native and invasive winter annual production in California deserts. Oecologia, 162(4): 1035-1046.

Reynolds H L, Mittelbach G G, Houseman G R, et al. 2007. No effect of varying soil resource heterogeneity on plant species richness in a low fertility grassland. Journal of Ecology, 95: 723-733.

Rikiishi K, Hashiya E, Imai M. 2004. Linear trends of the length of snow-cover season in the Northern Hemisphere as observed by the satellites in the period 1972-2000. Annals of Glaciology, 38: 229-237.

Schmiedel U, Dengler J, Etzold S. 2012. Vegetation dynamics of endemic-rich quartz fields in the Succulent Karoo, South Africa, in response to recent climatic trends. Journal of Vegetation Science, 23: 292-303.

Shabanov N V, Zhou L M, Knyazikhin Y, et al. 2002. Analysis of interannual changes in northern vegetation activity observed in
AVHRR data from 1981 to 1994. IEEE Transactions on Geoscience and Remote Sensing, 40: 115-130.

Stevens C J, Duprè C, Dorland E, et al. 2010. Nitrogen deposition threatens species richness of grasslands across Europe. Environmental Pollution, 158(9): 2940-2945.

Stevens M H H, Carson W P. 2002. Resource quantity, not resource heterogeneity, maintains plant diversity. Ecology Letters, 5(3): 420-426.

Suding K N, Collins S L, Gough L, et al. 2005. Functional- and abundance-based mechanisms explain diversity loss due to $\mathrm{N}$ fertilization. PNAS, 102(12): 4387-4392.

Vitousek P M, Aber J D, Howarth R W, et al. 1997. Human alteration of the global $\mathrm{N}$ cycle: sources and consequences. Ecology Application, 7(3): 737-750.

Walker D A, Halfpenny J C, Walker M D, et al. 1993. Long-term studies of snow-vegetation interactions. BioScience, 43: 287-301.

Wang X Q, Jiang J, Wang Y C, et al. 2006. Response of ephemeral plant germination and growth to water and heat conditions in the southern part of Gurbantunggut Desert. Chinese Science Bulletin, 51(1): $110-116$.

Weltzin J F, Loik M E, Schwinning S, et al. 2003. Assessing the response of terrestrial ecosystems to potential changes in precipitation. BioScience, 53(10): 941-952.

Went F W. 1942. The dependence of certain annual plants on shrubs in southern California deserts. Bulletin of the Torrey Botanical Club, 69: 110-114.

Went F W. 1949. Ecology of desert plants. II. the effect of rain and temperature on germination and growth. Ecology, 30(1): 1-13.

Xu H, Li Y, Xu G Q, et al. 2007. Ecophysiological response and morphological adjustment of two Central Asian desert shrubs towards variation in summer precipitation. Plant, Cell and Environment, 30: 399-409.

Xu M, Lu A H, Xu F, et al. 2008. Seasonal chemical composition variations of wet deposition in Urumchi, northwestern China. Atmospheric Environment, 42: 1042-1048.

Yang H J, Huang Z A, Ye Y Z, et al. 2010. Effects of soil moisture profile on seedling establishment in the psammophyte Hedysarum laeve in the semiarid Otindag Sandland, China. Journal of Arid Environments, 74(3): 350-354.

Yang H J, Li Y, Wu M Y, et al. 2011. Plant community responses to nitrogen addition and increased precipitation: the importance of water availability and species traits. Global Change Biology, 17: 2936-2944.

Zhang Q H, Zak J C. 1998. Effects of water and nitrogen amendment on soil microbial biomass and fine root production in a semi-arid environment in West Texas. Soil Biology and Biochemistry, 30: 39-45.

Zhou X B, Zhang Y M, Ji X H, et al. 2011. Combined effects of nitrogen deposition and water stress on growth and physiological responses of two annual desert plants in northwestern China. Environmental and Experimental Botany, 74: 1-8. 